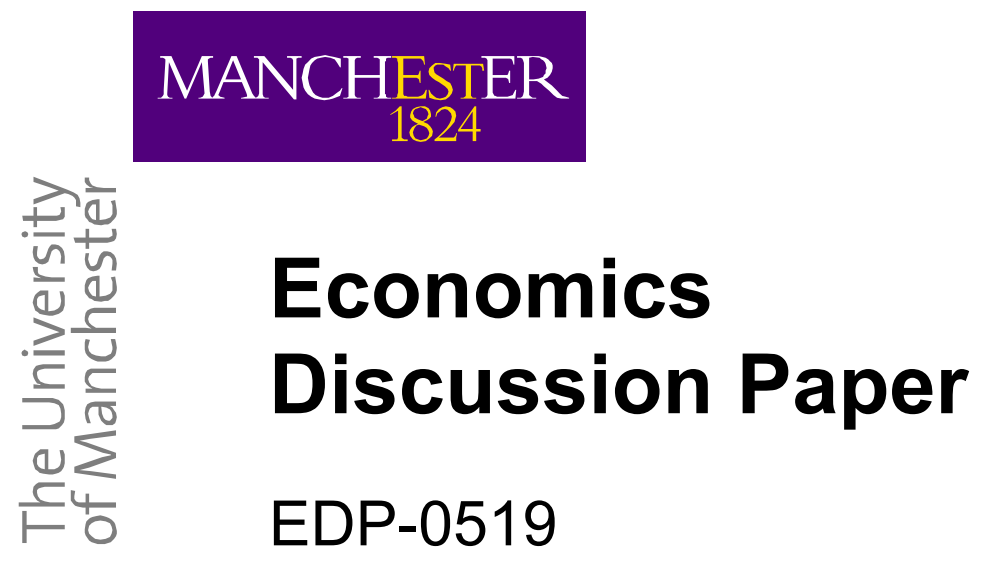

Welfare, home market effects, and horizontal foreign direct investment

by

Kristian Behrens and Pierre M. Picard

August 2005

pierre.picard@manchester.ac.uk

School of Social Sciences,

The University of Manchester

Oxford Road

Manchester M13 9PL

United Kingdom 


\title{
Welfare, home market effects, and horizontal foreign direct investment*
}

\author{
Kristian Behrens $^{\dagger} \quad$ Pierre M. Picard ${ }^{\ddagger}$
}

August 8, 2005

\begin{abstract}
A bstract
We investigate the spatial distribution and organization of an imperfectly competitive industry when firms may choose to operate more than a single production unit. Focusing on a short-run setting with a fixed mass of firms, we fully characterize the spatial equilibria analytically. Comparing the equilibrium and the first-best, we show that both organizational and spatial inefficiencies may arise. In particular, when fixed costs are low enough the market outcome may well lead to overinvestment and, therefore, to too many multinationals operating from a social point of view. Furthermore, once multinationals are taken into account, the market outcome may well lead too little agglomeration.
\end{abstract}

Keywords: international trade; imperfect competition; horizontal foreign direct investment; economic geography

JEL Classification: F12; F23; R12

${ }^{*}$ We thank Takaaki Takahashi and Eric Toulemonde for very helpful comments and suggestions.

†CORE, Université catholique de Louvain, 34 voie du Roman Pays, 1348 Louvain-la-Neuve, Belgium. Office: +3210474305. E-mail: behrens@c or e. ucl . ac. be

${ }^{\ddagger} \mathrm{CORE}$, Université catholique de Louvain, Belgium; and University of Manchester, England. E-mail: pierre.picard@manchester.ac.uk, picard@core.ucl,ac.be 


\section{Introduction}

It is fair to say that multinational enterprises (henceforth, MNEs) are key players in the world economy and that their importance has been increasing recently. Indeed, estimates suggest that MNEs may be responsible for as much as $75 \%$ of world commodity trade and that they account for the major share of intra-industry trade, itself a large part of world trade (see Dunning, 1993; Barba Navaretti and Venables, 2004). Recently, inward and outward foreign direct investment (henceforth, FDI) for the OECD countries amounted to USD 384.4 billion and 576.3 billion in 2003, respectively (OECD, 2004). Yet, despite their importance in shaping the international economy and the structure of world trade, the desirability of multinational firms is a much less debated topic. As Barba Navaretti and Venables (2004, pp. IX and 1) put it:

\footnotetext{
"Depending on your point of view, multinational enterprises are either the heroes or the villains of the globalized economy [... T The Dr Jekyll and Mr Hyde perception of MNEs stems more from the ambiguous feelings often directed towards large market players with no national identity than from rigorous economic analysis. Indeed, the debate on MNEs is rarely grounded in economic arguments and there is little understanding of what MNEs are, and what the sound reasons for liking or disliking them are."
}

In the present paper, we develop a simple model of horizontal FDI in the presence of product differentiation, imperfect competition, trade costs, and size asymmetries between countries. In so doing, we tie more closely together two quite distinct strands of the literature on multinational firms, namely the one analyzing the location and production decisions of a single firm using a quasi-linear quadratic specification, which allows to get concise analytical results (e.g., Haufler and Wooton, 1999; Haaland and Wooton, 2000); and the one focusing on differentiated products and the interaction of a large number of firms within an industry (e.g., Markusen and Venables, 1998, 2000; Barba Navaretti 
and Venables, 2004). Our model combines both approaches in a concise way, provides a full analytical characterization of the equilibria, and compares the market outcome with the optimum. ${ }^{1}$ Our results confirm the (mostly numerical) findings derived by Markusen and Venables (1998, 2000), Raybaudi-Massilia (2000) and Ekholm and Forslid (2001), which have been empirically highlighted by Brainard (1997), using an alternative modelling framework: ${ }^{2}$ larger market size, more symmetric countries, higher trade costs, and lower fixed costs for establishing a foreign subsidiary all raise the occurrence of MNEs in equilibrium, whereas smaller market size, asymmetric countries, lower trade costs and higher fixed costs raise the occurrence of exporters. When fixed costs are either high or low, the spatial equilibrium involves only exporters or only multinationals, respectively; whereas for intermediate values of fixed costs all types of firms may coexist in both countries. Finally, when all types of firms coexist, the exporting firms are located mainly in the larger country because market size matters in the presence of increasing returns and transport costs. Yet, the so-called 'home market effect' (henceforth, HME; Krugman, 1980; Helpman and Krugman, 1985), namely that firms locate disproportionately in the larger country which becomes a net exporter of the goods produced under increasing returns, need not arise in the presence of MNEs. The reason for this is that trade and horizontal FDI are substitutes, which reduces trade flows and therefore provides a potential explanation of why the HME may be difficult to find in international trade data (see,

\footnotetext{
${ }^{1}$ Note that our analysis is static and, therefore, disregards all 'dynamic' gains from FDI, e.g., technology transfer or increases in productivity. Yet, these gains may be quite significant (Barba Navaretti and Venables, 2004). We also neglect the presence of communication costs between headquarters and production plants, and the impacts of changes in these on the production organization of the industry (see, e.g., Fujita and Thisse, 2005).

${ }^{2}$ Markusen and Venables (1998) focus on homogeneous goods and quantity competition, whereas our model includes differentiated goods and price competition. Ekholm and Forslid (2001) assume perfect labor mobility, whereas our model assumes immobile labor. Finally, Raybaudi-Massilia (2000) presents a model with immobile labor, but she restricts her attention to simulation results.
} 
e.g., Davis and Weinstein, 2003; Head and Ries, 2003).

Turning to the normative analysis of MNEs, our main result shows that there are two potential inefficiencies in the space-economy. First, too many exporting firms are generally clustered into the larger country, i.e., there is too much agglomeration in equilibrium (Ottaviano and Thisse, 2002). Second, the presence of multinationals may lead to organizational inefficiencies in the sense that there can be either over-or under-investment in production plants. In particular, when the fixed costs for establishing a second plant are low enough, too many firms may 'go multinational'. The reason underlying this result is that a larger number of MNEs increases competition and decreases prices in the global economy, which makes market access for exporting firms more difficult when compared to local sales of MNEs. Thus, even more firms will decide to 'go multinational' since exporting is not the best option. In such a case, the resource waste of establishing a second plant may well not be compensated by sufficient transport cost savings. It is of interest to note that this result contrasts starkly with what is known in the alternative CES setting, in which there is always under-investment with respect to the first-best due to the absence of pro-competitive effects (Toulemonde, 2004).

The remainder of the paper is organized as follows. In Section 2, we present the model and derive the market outcome. Section 3 discusses the spatial equilibrium. Sections 4 investigates the optimal outcome and Section 5 compares it with the equilibrium. Section 6 discusses our results and investigates their robustness under alternative modeling assumptions. Section 7 concludes and points towards future research directions.

\section{The model}

Our model extends the framework of Ottaviano et al. (2002) and Ottaviano and Thisse $(2002,2004)$ to include multinational firms. In this section, we develop the basic model and characterize the market outcome for any given organizational structure and spatial 
distribution of firms.

\subsection{Preferences}

Consider a world with two countries, labeled $H$ and $F$. Variables associated with each country will be subscripted accordingly. We assume that there is a mass $L$ of consumers, with a share $1 / 2<\theta<1$ located in country $H$. In what follows, we refer to $H$ as the 'large' country. All consumers in countries $i=H, F$ have identical quasi-linear preferences over a homogeneous good and a continuum of $N$ varieties of a horizontally differentiated good. The subutility over the varieties $v \in[0, N]$ of the manufactured good is quadratic:

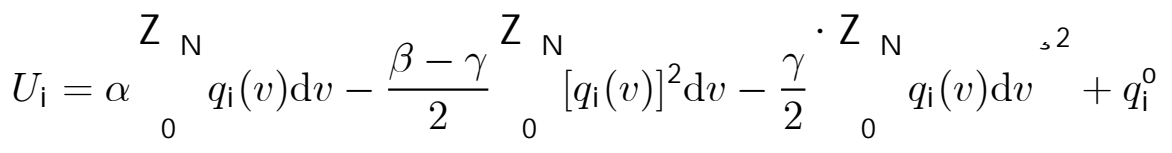

where $q_{\mathrm{i}}(v)$ denotes the consumption of variety $v, q_{\mathrm{i}}^{\mathrm{O}}$ stands for the consumption of the homogeneous good, and where $\alpha>0, \beta>\gamma>0$ are utility parameters.

All consumers are endowed with one unit of labor, $K / L$ units of capital, and $\bar{q}^{\mathrm{o}}>0$ units of the homogeneous good. Both labor and capital are supplied inelastically. The homogeneous good is produced under perfect competition using one unit of labor only, and we assume that the homogenous good can be costlessly traded between countries. Hence we can choose the latter as the numéraire, i.e., $p_{\mathrm{i}}^{\mathrm{o}}=p^{0}=1$. Each agent maximizes her utility (1) subject to her budget constraint:

$$
{ }_{0}^{Z_{\mathrm{N}}} p_{\mathrm{i}}(v) q_{\mathrm{i}}(v) \mathrm{d} v+q_{\mathrm{i}}^{\mathrm{o}} \leq w_{\mathrm{i}}+\frac{K}{L} r_{\mathrm{i}}+\bar{q}^{\mathrm{o}},
$$

where $p_{\mathrm{i}}(v)$ is the consumer price of variety $v, w_{\mathrm{i}}$ is the wage and $r_{\mathrm{i}}$ is the rental rate of capital that an individual in country $i$ faces. As in Ottaviano et al. (2002), we assume that the endowment of the homogenous good $\bar{q}^{\mathrm{O}}$ is large enough for agents to consume this good in equilibrium $\left(q_{\mathrm{i}}^{\mathbf{O}}>0\right)$. As a result, the demands for the differentiated goods include no income effects. In particular, the allocation of profits to shareholders and the location where these profits are generated are immaterial for the consumption of the differentiated 
good. Maximizing the utility (1) subject to (2), we obtain the following demands:

$$
q_{\mathrm{i}}(v)=a-(b+c N) p_{\mathrm{i}}(v)+c_{0}^{\mathbf{Z}_{\mathrm{N}}} p_{\mathrm{i}}(v) \mathrm{d} v,
$$

where $a, b$ and $c$ are positive coefficients given by

$$
a \equiv \frac{\alpha}{\beta+(N-1) \gamma} \quad b \equiv \frac{1}{\beta+(N-1) \gamma} \quad c \equiv \frac{\gamma}{(\beta-\gamma)[\beta+(N-1) \gamma]}
$$

\subsection{Technology, trade costs, and factor mobility}

We assume that each manufacturing firm $v \in[0, N]$ produces a single variety, e.g., because of a patent right or the absence of scope economies. Hence, the total mass of varieties $N$ also stands for the total mass of firms in the global economy. Firms not only choose their location but also choose the number of plants they operate: either a single plant only, or one plant in each of the two countries. Stated differently, firms make both an organizational and a locational choice in our model since they decide whether they will be single- or multi-plant. ${ }^{3}$ We denote by $n_{\mathrm{i}}$ the mass of single-plant firms based in country $i=H, F$, and by $m$ the mass of multi-plant firms, respectively. ${ }^{4}$ The total mass of varieties and, therefore, of firms is given by

$$
N=n_{\mathrm{H}}+n_{\mathrm{F}}+m
$$

Given the fact that MNEs operate two plants, the mass of production plants is then given by $n_{\mathrm{H}}+n_{\mathrm{F}}+2 m \geq N$. The demand for each variety depends on the mass of varieties produced domestically and on the mass produced abroad. The mass of varieties produced in country $H$ (resp., in country $F$ ) is equal to $N_{\mathrm{H}}=n_{\mathrm{H}}+m\left(\right.$ resp., $\left.N_{\mathrm{F}}=n_{\mathrm{F}}+m\right)$.

\footnotetext{
${ }^{3}$ In the remainder of this paper we use the terms multinationals, multi-plant firms, and MNEs interchangeably.

${ }^{4}$ Note that we do not need to keep track of where multi-plant firms are headquartered. This is because we assume that headquarter fixed costs are the same in both countries. When fixed costs differ, headquarters will be exclusively located in the low fixed cost country (see Barba Navaretti and Venables, 2004, p.54).
} 
As will become clear later, the mass of varieties imported from country $F$ (resp., from country $H$ ) is equal to $n_{\mathrm{F}}$ (resp., $n_{\mathrm{H}}$ ) because local production and imports of the same variety do not occur in equilibrium.

Labor is assumed to be internationally immobile but perfectly mobile across sectors. As usual in the literature, we assume unit labor productivity in the perfectly competitive and costlessly tradable numéraire sector which, by arbitrage, yields a unit wage $w_{\mathrm{i}}=1$ for all workers in both countries. In the differentiated goods sector, all manufacturing firms have identical production functions which involve fixed and variable costs incurred in capital and in labor, respectively. On the one hand, the variable labor requirement can be normalized to zero without loss of generality. Indeed, as mentioned by Ottaviano et al. (2002), a change in variable cost is equivalent to a rescaling of consumers' demand intercepts. On the other hand, each firm's fixed cost depends on the number of plants it operates. A firm requires $f$ units of capital to set up its primary production plant, and $\xi f$ additional units of capital to set up a secondary production plant in the other country. When $0<\xi<1$, there exist firm-level scale economies since the fixed costs of the second plant are smaller than those of the first one. This may capture the fact that a share $(1-\xi) f$ of capital is required for $\mathrm{R} \& \mathrm{D}$ or general management, whereas only $\xi f$ units are used for production per se. By contrast, when $\xi>1$ there exist firm-level scale diseconomies. This may reflect the additional coordination, control and management costs (overhead costs) created by distant business units. In the main part of the paper we assume that the rental rate of capital is exogenously fixed and, without loss of generality., we normalize it to one: $r_{\mathrm{i}} \equiv r=1, i \in\{H, F\}$. Constant rental rates may reflect a constant degree of lenders' rate of intertemporal substitution, or they may result from the fact that the industry is small when compared to the rest of the economy (because either countries or industries are small enough). The capital supply is then infinitely elastic, which implies that the mass of firms and varieties is constant and equal to $N$. In Section 6, we relax this assumption by considering less elastic supplies of capital which leads to 
a variable mass of firms. Finally, shipping each variety of the manufactured good across countries entails a per-unit cost of $\tau>0$ units of the numéraire, whereas shipping it within each country is free.

Given the set of assumptions outlined in the above, firms play the following two-stage game: (i) all firms simultaneously choose the number and location of their production plants; and (ii) given their previous choices, all firms set profit maximizing prices in each market separately. We derive the price equilibrium of the second stage in the next sub-section and then present firms' locational and organizational choices in Section 3.

\subsection{Price equilibrium}

Assume that $n_{\mathrm{H}}, n_{\mathrm{F}}$ and $m$ are given. Because all varieties produced in the same country may be treated symmetrically, the demands for varieties produced in country $i$ and consumed in country $j$ can be expressed as follows:

$$
q_{\mathrm{ij}}=a-(b+c N) p_{\mathrm{ij}}+c P_{\mathrm{j}}
$$

where $P_{\mathrm{j}} \equiv N_{\mathrm{j}} p_{\mathrm{jj}}+N_{\mathrm{i}} p_{\mathrm{ij}}$ with $i \neq j$.

Since each firm is negligible, it sets its own prices taking as given all other variables. In accord with empirical evidence (e.g., Head and Mayer, 2000; Haskel and Wolf, 2001), we assume that markets are segmented. Firms are hence free to set prices specific to each national market they sell their product in. Superscripting variables pertaining to single-plant firms by $s$ and to multi-plant firms by $m$, the profit of a single-plant firm established in country $H$ is given by

$$
\Pi_{\mathrm{H}}^{\mathrm{s}}=L \theta p_{\mathrm{HH}} q_{\mathrm{HH}}+L(1-\theta)\left(p_{\mathrm{HF}}-\tau\right) q_{\mathrm{HF}}-f,
$$

whereas the profit of a multi-plant firms is given by

$$
\Pi^{\mathrm{m}}=L \theta p_{\mathrm{HH}} q_{\mathrm{HH}}+L(1-\theta) p_{\mathrm{FF}} q_{\mathrm{F} \mathrm{F}}-(1+\xi) f .
$$


To shorten exposition, we derive all expressions for country- $H$ firms only, symmetric expressions holding for country- $F$ firms. As can be seen from (4) and (5), we assume that multi-plant firms behave like local firms in each domestic market and serve each market through 'subsidiary sales' only. Indeed, given plant-level scale economies, transport costs, and the absence of capacity constraints, the firm will never produce a fraction of demand locally while importing the rest from abroad.

Since multi-plant firms serve each market locally, their domestic pricing decisions are identical to those of the single-plant firms operating in the same market. Maximizing the profits $(4)$ and (5) with respect to $p_{\mathrm{HH}}$ and $p_{\mathrm{HF}}$, substituting the price aggregate and solving for the equilibrium prices and quantities yields:

$$
\begin{gathered}
p_{\mathrm{H} H}^{*}=\frac{2 a+c N \tau-c\left(m+n_{\mathrm{H}}\right) \tau}{2(2 b+c N)}=\frac{2 a+c n_{\mathrm{F}} \tau}{2(2 b+c N)}, \quad p_{\mathrm{FH}}^{*}=p_{\mathrm{H} H}^{*}+\frac{\tau}{2} \\
q_{\mathrm{HH}}^{*}=(b+c N) p_{\mathrm{HH}}^{*}, \quad q_{\mathrm{FH}}^{*}=(b+c N)\left(p_{\mathrm{FH}}^{*}-\tau\right) .
\end{gathered}
$$

As can be seen from $(6)$, both $p_{\mathrm{HH}}^{*}$ and $p_{\mathrm{FH}}^{*}$ decrease with the mass of plants located in country $H$, i.e., $m+n_{\mathrm{H}}$. Note that the mass of multi-plant firms influences all equilibrium prices. Hence, whereas single-plant firms have an impact only on the prices in the country they are located in, multi-plant firms put a downward pressure on prices in both countries. As a result, when $\tau>0$ an increase in the number of multi-plant firms raises competition everywhere and reduces profits in both countries.

In what follows, we assume that trade costs are sufficiently low such that international trade is always feasible. It is readily verified that $q_{\mathrm{ij}}^{*}>0$ for all $\left(n_{\mathrm{i}}, n_{\mathrm{j}}, m\right)$ and $i \neq j$ provided that

$$
\tau<\tau^{\text {trade }} \equiv \frac{2 a}{2 b+c N}
$$

Condition (8), which is henceforth referred to as trade feasibility condition, also makes sure that export prices $p_{\mathrm{ij}}^{*}$ net of transport costs $\tau$ remain strictly positive for all firm 
distributions. For the sake of simplicity, we furthermore assume that all varieties are produced in equilibrium. To this aim we assume that a single-plant firm can always profitably operate in its local market for all possible values of trade $\operatorname{costs} \tau$ and all spatial and organizational structures of the economy. Using the most restrictive case where all firms are multi-plant and where $\tau=\tau_{\text {trade, }}$ this will be the case when

$$
f \leq \frac{L(b+c N)}{8}\left(\tau^{\text {trade }}\right)^{2}
$$

Condition (9), which is henceforth referred to as firms' profitability constraint makes sure that all types of firms always make positive profits for all possible structures of the economy. Note that we can always set a sufficiently high value of $L$ to satisfy this constraint.

Using expression (7) the profits of single- and multi-plant firms can finally be expressed as follows:

$$
\begin{aligned}
& \Pi_{\mathrm{H}}^{\mathrm{s}}=\theta L(b+c N)\left(p_{\mathrm{H} H}^{*}\right)^{2}+(1-\theta) L(b+c N) p_{\mathrm{FF}}^{*}-\frac{\tau}{2}^{\prime 2}-f \\
& \Pi^{\mathrm{m}}=\theta L(b+c N)\left(p_{\mathrm{H} H}^{*}\right)^{2}+(1-\theta) L(b+c N)\left(p_{\mathrm{FF}}^{*}\right)^{2}-(1+\xi) f .
\end{aligned}
$$

\section{Spatial equilibrium}

All firms simultaneously choose their production location and structure. Let us first focus on single-plant firms $(m=0)$. Evaluating the difference of single-plant firms' profits at the equilibrium prices (6) and quantities (7) yields the following profit differential:

$$
\Pi_{\mathrm{H}}^{\mathrm{S}}-\Pi_{\mathrm{F}}^{\mathrm{s}}=K^{\cdot \mu} \quad \theta-\frac{1}{2}(4 a-\tau(2 b+c N))+c \tau\left(\theta n_{\mathrm{F}}-(1-\theta) n_{\mathrm{H}}\right)^{\text {व }},
$$

where

$$
K \equiv \frac{L(b+c N) \tau}{2(2 b+c N)}>0
$$


Equating this profit differential to zero, we readily obtain the mass of firms in countries $H$ and $F$ :

$$
n_{\mathrm{H}}^{*}=\frac{N}{2}+(2 \theta-1) \frac{2 a-\tau b}{c \tau} \quad \text { and } \quad n_{\mathrm{F}}^{*}=N-n_{\mathrm{H}}^{*}
$$

which corresponds to the expressions of Ottaviano and Thisse (2004).

Suppose now that firms may choose to run several production plants. Expression (10) is an equilibrium if and only if no single-plant firm can profitably invest abroad, which implies to evaluate the difference between multi-plant and single-plant firms' profits

$$
\Pi^{\mathrm{m}}-\Pi_{\mathrm{H}}^{\mathrm{s}}=L(1-\theta)(b+c N) \tau^{3} p_{\mathrm{FF}}^{*}-\frac{\tau^{\prime}}{4}-\xi f .
$$

To ease the exposition, let us define

$$
\bar{\theta} \equiv \frac{1}{2}+\frac{1}{4} \frac{\tau c N}{2 a-b \tau}>\frac{1}{2}
$$

and

$$
\begin{gathered}
A_{\mathrm{H}} \equiv \frac{K[4 a-(2 b+c N) \tau](1-\theta)}{2} \quad A_{\mathrm{F}} \equiv \frac{K[4 a-(2 b+c N) \tau] \theta}{2} \\
A_{0} \equiv 2 K(2 a-\tau b) \theta(1-\theta),
\end{gathered}
$$

which are all positive coefficients under the trade feasibility condition (8). It is readily verified that $A_{\mathrm{H}}<A_{\mathrm{F}}<A_{0}$ for all $\theta<\bar{\theta}$, whereas $A_{\mathrm{H}}<A_{0}<A_{\mathrm{F}}$ when $\theta>\bar{\theta}$.

Using (6) and (7), some standard calculations show that (11) is positive if and only if

$$
n_{\mathrm{H}}>\bar{n}_{\mathrm{H}} \equiv \frac{\xi f-A_{\mathrm{H}}}{c \tau(1-\theta) K} .
$$

The analogous condition for country $F$ (i.e., $\Pi^{\mathrm{m}}-\Pi_{\mathrm{F}}^{\mathrm{s}}>0$ ) is given by

$$
n_{\mathrm{F}}>\bar{n}_{\mathrm{F}} \equiv \frac{\xi f-A_{\mathrm{F}}}{c \tau \theta K}
$$

Finally, on can verify that $n_{\mathrm{H}}^{*}<\bar{n}_{\mathrm{H}}$ if and only if $\xi f>A_{0}$. 
Expression (12) shows that single-plant firms in country $H$ decide to become multiplant when the mass of single-plant firms located there exceeds the critical mass $\bar{n}_{\mathrm{H}}$. Stated differently, firms are enticed to become multi-plant if they are located in a country hosting many firms.

Because $\theta>1 / 2$ we have that $\bar{n}_{\mathrm{H}}>\bar{n}_{\mathrm{F}}$. Firms in the larger country have indeed 'less incentives' to become multi-plant because they serve the larger share of demand locally. A direct consequence of the size asymmetries between countries is that we may observe asymmetric situations, in which only exporting firms located in the smaller country decide to open a second production plant in the larger foreign market. Note also that $\bar{n}_{\mathrm{H}}$ and $\bar{n}_{\mathrm{F}}$ can be positive or negative, depending on the relative size of $\xi, \tau$ and $\theta$.

Conditions (12) and (13) illustrate several important aspects. First, if $\xi$ is sufficiently small (i.e., plant-level scale economies are small when compared to firm-level scale economies), firms will always want to run a second production plant. The same occurs of course when transport $\operatorname{costs} \tau$ are sufficiently large, provided that trade remains feasible. Second, when demand ( $a$ and $L$ ) in the global economy is sufficiently large, firms will also become multi-plant since they would incur more (overall) transport costs otherwise. All these results are in accord with what is known in the case of horizontal FDI (Markusen and Venables, 1998, 2000; Barba Navaretti and Venables, 2004).

\subsection{Equilibrium}

Since the equilibrium configurations depend on $\xi f$ and $\theta$, our results are best conveyed using a graphical representation as in Figures 1 and 2. A formal description of the equilibria, including all proofs, are given in Appendix A.

\section{INSERT FIGURES 1 AND 2}

The equilibrium location and structure of firms requires to distinguish between several cases, depending on how $\xi f$ compares to the thresholds $A_{\mathrm{H}}, A_{\mathrm{F}}$ and $A_{0}$. Figure 1 depicts 
the spatial equilibrium as a function of the capital requirement $\xi f$ for a second plant when size asymmetries between countries are small (i.e., $\theta<\bar{\theta}$ ). ${ }^{5}$ The heights between two curves represent the number of firms in each configuration, which are all linear functions of $\xi f$. As can be seen, when $\xi f \leq A_{\mathrm{H}}$, there are only multi-plant firms. This is because the cost of a second plant is low enough so that exporting is never an optimal choice. When $A_{\mathrm{H}}<\xi f<A_{\mathrm{F}}$, exporting becomes a viable option and some firms start shuttingdown plants in the small country $F$ and relocate all their production activity to the large country $H$. The equilibrium involves both single- and multi-plant firms but singleplant firms agglomerate in the larger country. As the cost of a second plant increases further $\left(A_{\mathrm{F}}<\xi f<A_{0}\right)$, more and more firms turn to an export-oriented production structure. The equilibrium involves both single- and multi-plant firms and single-plant firms unequally disperse across both countries. Finally, when the cost of a second plant becomes too large $\left(\xi f>A_{0}\right)$, multi-plant operation is no longer feasible and there are only exporting firms. In that case, the larger country $H$ hosts a more than proportionate share of the firms. Indeed, single-plant firms locate in the larger country because of the HME which makes them serve the larger fraction of their demand locally.

Until now, we have assumed that the size asymmetries between countries are sufficiently small $(\theta<\bar{\theta})$. As $\theta$ gradually increases, the zone for a pure multi-plant configuration shrinks, whereas the occurence of an interior equilibrium decreases (the slopes in the middle part of Figure 1 become steeper). Once countries differ sufficiently (i.e., $\theta \geq \bar{\theta}$ ), there are no more equilibria in which both single- and multi-plant firms coexist. In that case, which is depicted by Figure 2, all firms are multi-plant when the costs of a second plant are low enough $\left(\xi f<A_{\mathrm{H}}\right)$, whereas all firms will be single-plant exporters located in the large country $H$ when plant costs are high enough $\left(\xi f \geq A_{\mathrm{H}}\right)$. Stated differently, as plant costs rise, the location structure discontinuously switches from a pure multi-plant

\footnotetext{
${ }^{5}$ The parameter values in Figure 1 are as follows: $\alpha=1, \beta=1, \gamma=1 / 2, N=5, L=10, \phi=1$, $r=1, \tau=0.22$ and $\theta=0.54$. In Figure 2 , we set $\theta=0.7$.
} 
situation with full dispersion of production to a pure single-plant situation with full agglomeration of production. The reason for such a change is that the agglomeration forces generated by the larger region are too strong to make production profitable in the smaller country. As a consequence, all firms will cluster into the large country once the fixed costs of a second plant are sufficiently low.

\subsection{Comparative statics}

Figures 1 and 2 can easily be used to present some comparative static results with respect to the size of demand, transport costs, and plant-level fixed costs. Indeed, all the thresholds $A_{\mathrm{H}}, A_{\mathrm{F}}$ and $A_{0}$ increase in the size of demand ( $a$ and $L$ ), decrease in demand elasticity (smaller $b$ ) and increase in transport cost $(\tau)$. Hence, increases in demand or transport costs, or decreases in the demand elasticity are mathematically equivalent to a reduction of $\xi f$, thus raising the likelihood of firms becoming multi-plant. Intermediate values of demand and transport costs give rise to either agglomeration in the larger country or to equilibria with all types of firms.

Our results also neatly illustrate how size asymmetries matter for multi-plant firms. Figure 3 displays the equilibrium configurations for various sizes of countries $\left(L_{\mathrm{H}}, L_{\mathrm{F}}\right)=$ $(\theta L,(1-\theta) L)$ when $L_{\mathrm{H}} \geq L_{\mathrm{F}}$. The labels in each area denote the types of firms that are active at the equilibrium. For instance, $n_{\mathrm{H}}$ means that the equilibrium includes only single-plant firms in country $H$. Figure 3 shows that the absolute and relative sizes of regions are two important determinants of industry structure. First, when the absolute country sizes are large, the equilibrium involves only multi-plant firms, whatever agglomeration forces may exist. The reason for this is that, by running two plants, firms avoid transport costs on large bulks of exports when both countries are large. Relative size asymmetries have no impact on the distribution of firms and plants. Second, when absolute country sizes are small, relative sizes do matter for the location of economic 
activity. Similar country sizes imply single-plant firms in both countries, whereas size differences push firms to locate in the larger country only. Finally, when absolute country sizes take intermediate values, an increase in the relative size of the larger country firstly decreases the number of single-plant firms in the smaller country and then reduces the number of firms building a second plant in this country. This suggests, as in Markusen and Venables (1998) and Barba Navaretti and Venables (2004, ch.3), that multi-plant firms are more likely to be observed in large and symmetric countries.

\section{INSERT FIGURE 3 HERE}

\subsection{Home market effect}

It is instructive to measure to which extent the HME arises in the various configurations of our model. To reduce the number of cases, we assume in what follows that $\theta<\bar{\theta}$. First, consider that no firm decides to become multinational, which happens when the cost of a second plant is large $\left(\xi f>A_{0}\right)$. Similarly to Ottaviano and Thisse (2004), one can then check that the HME shows up in the model in this case. Indeed, using expression (10), the 'market size bias' in the international distribution of firms is given by:

$$
\frac{n_{\mathrm{H}}^{*}-n_{\mathrm{F}}^{*}}{N}=(2 \theta-1) \frac{2(2 a-\tau b)}{c \tau N}
$$

which is always larger than the population bias $\left(L_{\mathrm{H}}-L_{\mathrm{F}}\right) / L=2 \theta-1$ by the trade feasibility condition (8). Although firms relax competition by dispersing themselves across the two countries, they minimize transport costs by locating production in the larger country where they can serve the larger demand locally. In equilibrium, these two forces must be balanced so that the larger country hosts a more than proportional share of the industry.

Does the home market effect still arise in the presence of multi-plant firms? Consider now the equilibria involving both single- and multi-plant firms in every country $\left(A_{\mathrm{F}} \leq\right.$ 
$\left.\xi f \leq A_{0}\right)$. As shown in Appendix A, the spatial equilibrium is such that $n_{\mathrm{H}}^{*}=\bar{n}_{\mathrm{H}}$ and $n_{\mathrm{F}}^{*}=\bar{n}_{\mathrm{F}}$, so that the market size bias in the international distribution of firms is equal to

$$
\frac{\left(\bar{n}_{\mathrm{H}}+m\right)-\left(\bar{n}_{\mathrm{F}}+m\right)}{N}=\frac{\bar{n}_{\mathrm{H}}-\bar{n}_{\mathrm{F}}}{N}=\frac{1}{\theta(1-\theta)} \frac{2 \theta-1}{c \tau N K} \xi f .
$$

It can be verified that this expression is smaller than (14) whenever $A_{0}<\xi f$, a condition that must hold for multi-plant firms to operate. As a result, the HME gets weaker in the presence of multi-plant firms than in their absence. Moreover, one can check when a HME arises in the configuration with multi-plant firms. It is readily verified that country $H$ hosts a more than proportional industry share if and only if

$$
\theta(1-\theta)<\frac{\xi f}{c N \tau K}
$$

This will not be the case (i) if countries' size asymmetries are small; or (ii) if the costs $\xi f$ of a second plant are low; or (iii) if transport $\operatorname{costs} \tau$ and the mass $L$ of population are large. Stated differently, the HME may vanish in the presence of multi-plant firms, which may be one cause for the relative absence of 'home market effects' in the international trade data.

We now compare the equilibrium location and organizational structure to the (firstbest) optimum location and structures. ${ }^{6}$

\section{Optimum}

In this section, we analyze whether the presence of MNEs is desirable from a global perspective. In doing so, we want to assess whether the global economy as a whole may benefit or loose from the presence of MNEs. Note that we do not investigate whether some countries may gain whereas others may loose, which is an important issue abundantly

\footnotetext{
${ }^{6}$ The second-best results are qualitatively very similar to the first-best results. We therefore omit them, but they are available upon request from the authors.
} 
discussed elsewhere in the literature (e.g., Markusen and Venables, 1999; Barba Navaretti and Venables, 2004).

The quasi-linear setup of our model is well suited to a full-fledged utilitarian welfare analysis, since utilities are transferrable. In the first-best, the planner is able to monitor firms' location, organizational structure, and prices. The planner equates prices to marginal costs, i.e., $p_{\mathrm{HH}}=p_{\mathrm{FF}}=0$ and $p_{\mathrm{HF}}=p_{\mathrm{FH}}=\tau$, and uses lump-sum transfers to compensate firms for the losses they incur under such a pricing policy. The planner thus maximizes the aggregate welfare which includes the total consumer surplus minus the total (fixed) cost of production:

$$
W=L\left[\theta S_{\mathrm{H}}+(1-\theta) S_{\mathrm{F}}\right]-f\left(n_{\mathrm{H}}+n_{\mathrm{F}}\right)-m(1+\xi) f .
$$

One can show that the consumer surplus in country $H$ is given by

$$
\begin{aligned}
S_{\mathrm{H}}= & \frac{a^{2} N}{2 b}-a\left[\left(n_{\mathrm{H}}+m\right) p_{\mathrm{HH}}+n_{\mathrm{F}} p_{\mathrm{FH}}\right]+\frac{b+c N}{2}^{f}\left(n_{\mathrm{H}}+m\right) p_{\mathrm{HH}}^{2}+n_{\mathrm{F}} p_{\mathrm{FH}}^{2} \stackrel{\mathfrak{a}}{ } \\
& -\frac{c}{2}\left[\left(n_{\mathrm{H}}+m\right) p_{\mathrm{HH}}+n_{\mathrm{F}} p_{\mathrm{FH}}\right]^{2},
\end{aligned}
$$

which reduces to

$$
S_{\mathrm{H}}=\frac{a^{2} N}{2 b}-a n_{\mathrm{F}} \tau+\frac{b+c N}{2} n_{\mathrm{F}} \tau^{2}-\frac{c}{2}\left(n_{\mathrm{F}} \tau\right)^{2}
$$

under marginal cost pricing. A symmetric expression holds for country $F$.

A first-best allocation is then a triple $\left(n_{\mathrm{H}}^{\circ}, n_{\mathrm{F}}^{\circ}, m^{\circ}\right)$ that maximizes the aggregate welfare $W$, subject to the constraints $m^{\circ}=N-n_{\mathrm{H}}^{\circ}-n_{\mathrm{F}}^{\circ}, n_{\mathrm{H}}^{\circ} \geq 0, n_{\mathrm{F}}^{\circ} \geq 0$ and $m^{\circ} \geq 0$. To ease the exposition, let

$$
\theta^{\circ} \equiv \frac{1}{2}+\frac{1}{2} \frac{\tau c N}{2 a-b \tau}>\frac{1}{2}
$$

and define the following four thresholds:

$$
B_{\mathrm{H}} \equiv(a-(b+c N) \tau / 2) \tau L(1-\theta) \quad B_{\mathrm{F}} \equiv(a-(b+c N) \tau / 2) \tau L \theta
$$




$$
B_{0} \equiv L \tau(2 a-b \tau) \theta(1-\theta) \quad B_{1} \equiv B_{\mathrm{H}}+c L N \tau^{2}(1-\theta),
$$

which play an analoguous role to the thresholds in the previous section. It is readily verified that $B_{1}>B_{\mathrm{H}}, B_{\mathrm{F}}>B_{\mathrm{H}}$ and $B_{0}>B_{\mathrm{H}}$ for all parameter values of the model. Furthermore, $\theta^{\circ}>\bar{\theta}$.

As in Section 3, the basic results concerning the first-best location and structure of firms are best conveyed graphically. The formal descriptions and proofs are relegated to Appendix B. ${ }^{7}$

\section{INSERT FIGURES 4 AND 5}

Figures 4 and 5 depict the first-best masses of multi- and single-plant firms, which are again linear functions of $\xi f$. As the reader can observe, the 'ranking' of the first-best configurations is very similar to the 'ranking' of equilibrium configurations as $\xi f$ changes: only multi-plant firms are chosen when $\xi f$ is sufficiently low, whereas we gradually switch to a pure single-plant configuration as $\xi f$ progressively increases. More specifically, when the size asymmetries are small enough as in Figure $4\left(\theta<\theta^{\circ}\right)$, the planner organizes production as follows: (i) only multi-plant firms for $\xi f<B_{\mathrm{H}}$; (ii) multi-plant firms and single-plant firms in the larger country for $B_{\mathrm{H}}<\xi f \leq B_{\mathrm{F}}$; and (iii) multi-plant firms and single-plant firms in every country if $B_{\mathrm{F}}<\xi f \leq B_{0}$; and (iv) only single-plant firms for $\xi f>B_{0}$. Ottaviano and Thisse (2002) discuss the case of single-plant firms and point out that the planner tends to allocate less single-plant firms to the larger country in order to reduce spatial inequalities. In that case, the market outcome usually provides too much agglomeration.

When size asymmetries are large as in Figure $5\left(\theta \geq \theta^{\circ}\right)$, the planner organizes production in a quite similar way. Yet, there is a major difference with respect to the market outcome, since there are configurations in which multi- and single-plant firms coexist.

\footnotetext{
${ }^{7}$ The parameter values in Figures 3 and 4 are the same as in Section 3 , except that we set $\theta=0.85$ in the second case.
} 
Hence, the planner may chose to retain some single-plant firms in both, whereas this never happens in equilibrium when $\theta>\bar{\theta}$. Stated differently, spatial inequalities are again reduced but there is still some form of agglomeration.

Comparative statics results on the first-best are also similar to those on the equilibrium as all the $B$ thresholds increase in $a, L$ and $\tau$ and decrease in $b$. Hence, increases in demand or transport costs, or decreases in the demand elasticity, are mathematically equivalent to a reduction of $\xi f$, thus raising the likelihood that the planner implements a production structure with multi-plant firms.

Is there a HME in the first-best? Focussing again on the case where $\theta<\bar{\theta}$, configurations with only single plant firms $\left(\xi f>B_{0}\right)$ yield the following market size bias in the international distribution of firms (see Appendix B):

$$
\frac{n_{\mathrm{H}}^{\circ}-n_{\mathrm{F}}^{\circ}}{N}=(2 \theta-1) \frac{2 a-b \tau}{c \tau N} .
$$

It is readily verified that this bias exceeds $(2 \theta-1)$ under the trade feasibility condition. By contrast, configurations with multi- and single-plant firms located in both countries $\left(B_{\mathrm{F}}<\xi f \leq B_{0}\right)$ yield a market size bias in the international distribution of firms equal to

$$
\frac{n_{\mathrm{H}}^{\circ}-n_{\mathrm{F}}^{\circ}}{N}=(2 \theta-1) \frac{\xi f}{L c \tau^{2} \theta(1-\theta) N},
$$

which depends on the cost of a second plant. Hence, there exist parameter values such that this bias is smaller than its equilibrium counterpart when there are only single-plant firms, thus showing again that the HME gets weaker or may be reversed in the presence of multinationals.

\section{Too many or too few multi-plant firms?}

Contrary to models with only single-plant firms, two types of inefficiencies may arise in the presence of multi-plant firms. First, there may be organizational inefficiencies, in the 
sense that firms do not choose to operate the socially efficient number of plants. Second, there may be spatial inefficiencies, in the sense that firms do not locate their production units in a socially efficient way. Whereas the second inefficiency has been repeatedly highlighted in economic geography (Ottaviano and Thisse, 2002; Baldwin et al., 2003) the first has not been much investigated until now.

We can establish the following proposition concerning the equilibrium and optimum number of MNEs. Let us define $S_{*}$ as the set of parameters $\xi f$ such that, compared to the first best, too few firms decide to become multi-plant (under-investment in plants, $m^{*}<m^{\circ}$ ) and the set $S^{*}$ such that, too many firms decide to become multi-plant (overinvestment in plants, $m^{*}>m^{\circ}$ ).

Proposition 1 Compared to the first-best, in equilibrium

- there exist a range of parameters $\xi f$ involving under-investment in plants $\left(\xi f \in S_{*} \neq\right.$ $\{\emptyset\}$, while $\left.S^{*}=\{\emptyset\}\right)$ if $A_{\mathrm{H}}<B_{\mathrm{H}}$ or, equivalently, if $\tau<\tau^{\mathrm{u}} \equiv \frac{2 \mathrm{~b}}{\mathrm{~b}+\mathrm{cN}} \tau^{\text {trade }}$;

- there exist a range of parameters $\xi f$ involving over-investment in plants $\left(\xi f \in S^{*} \neq\right.$ $\{\emptyset\}$, while $\left.S_{*}=\{\emptyset\}\right)$ if $\theta>\theta^{\circ}$ and $A_{\mathrm{H}}>B_{1}$, i.e., $\tau>4 a b /[(2 b+c N)(b-3 c N)]$.

In the remaining cases, there exists values of $\xi f$ associated with under-investment and other values associated with over-investment. More precisely, the sets $S_{*}$ and $S^{*}$ are non empty, contiguous, bounded and such that the elements of $S_{*}$ are smaller than those of $S^{*}$.

Proof. When size asymmetries are large $\left(\bar{\theta}<\theta^{\circ}<\theta<1\right)$, the comparison between the equilibrium and the first-best allocation is readily established. Indeed, $m^{*}$ discontinuously drops to zero at $\xi f=A_{\mathrm{H}}$, whereas $m^{\circ}$ continuously falls with $\xi f$ in the interval $\xi f \in\left[B_{\mathrm{H}}, B_{1}\right]$. Hence, if $A_{\mathrm{H}}<B_{\mathrm{H}}$, there are too few multi-plant firms (underinvestment) for all $\xi f \in S_{*}=\left(A_{\mathrm{H}}, B_{1}\right)$ whereas $S^{*}=\{\emptyset\}$. If $A_{\mathrm{H}}>B_{1}$, there are too many multi-plant firms (over-investment) for all $\xi f \in S^{*}=\left(B_{\mathrm{H}}, A_{\mathrm{H}}\right)$ whereas $S_{*}=\{\emptyset\}$. 
If $B_{\mathrm{H}}<A_{\mathrm{H}}<B_{1}$, there are too few multi-plant firms for $\xi f \in S_{*}=\left(B_{\mathrm{H}}, A_{\mathrm{H}}\right)$ and too many for $\xi f \in S^{*}=\left(A_{\mathrm{H}}, B_{1}\right)$.

When size asymmetries are small $\left(1 / 2<\theta<\bar{\theta}<\theta^{\circ}\right)$, the comparison between equilibrium and first-best can easily be performed by noting that the mass of multiplant firms is more sensitive to the level of fixed cost of a second plant in equilibrium than in the first-best. Stated differently, in any configuration, $m^{*}$ decreases faster than $m^{\circ}\left(\partial m^{*} / \partial(\xi f)<\partial m^{\circ} / \partial(\xi f)<0\right)$. Since $A_{0}<B_{0}$, we need to check the case where $A_{\mathrm{H}} \leq B_{\mathrm{H}}$ and where $A_{\mathrm{H}}>B_{\mathrm{H}}$. First, if $A_{\mathrm{H}} \leq B_{\mathrm{H}}$, we get $S_{*}=\left(A_{\mathrm{H}}, B_{0}\right)$ and $S^{*}=\{\emptyset\}$. Second, if $A_{\mathrm{H}}>B_{\mathrm{H}}$, then, as shown by Figure 6 , there exists $B^{\prime}$ such that $S_{*}=\left(B_{\mathrm{H}}, B^{\prime}\right)$ and $S^{*}=\left(B^{\prime}, B_{0}\right)$. It is easy to show that the same comparison holds using $B_{1}$ in place of $B_{0}$ when $1 / 2<\bar{\theta}<\theta<\theta^{\circ}$.

The intuition underlying Proposition 1, as depicted by Figure 6, is as follows.

\section{INSERT FIGURE 6}

First, under-investment in plants is due to a negative pecuniary externality. Indeed, when firms decide to become multi-plant they increase price competition, which benefits consumers. Yet, increasing competition hurts firms, which may lead them to adopt an export structure when trade costs are low and fixed costs are high, even if the resulting fall in consumer surplus is larger than firms' profit gain. Stated differently, prices may be too low to support the socially optimal number of multi-plant firms. Second, overinvestment occurs for large transport costs and small fixed costs of a second plant. In an equilibrium with single-plant firms only, single-plant firms set high prices when transport costs are large; in other words, single-plant firms tend to use trade barriers to push prices up. However, high prices also strongly entice firms to build a second plant in the foreign market. Indeed, one can show that a higher price in a country raise the sales revenue in that country faster if a firm builds a plant in that location than if it exports to it. Hence, when trade barriers are high enough, the incentives to invest in a second plant are large 
and over-investment may occur. Over-investment thus stems from a positive pecuniary externality between single- and multi-plant firms, which seems unnoticed until now in the literature. Note that such a result does not show up in the models building on the CES specification, in which there is always under-investment and too few multinationals in equilibrium (see, e.g., Toulemonde, 2004). This suggests that variable mark-ups and procompetitive effects play an important role in explaining the presence of over-investment.

Finally, one should also note that since trade costs seem to be quite low nowadays, under-investment could be more likely to occur than over-investment. This suggests that the fears of too many multinationals operating in the global economy may be misplaced. ${ }^{8}$

The above discussion so far focuses on the organizational inefficiencies only. We now turn to the locational inefficiencies. To do so, let us define excess agglomeration as the larger country hosting too many plants in equilibrium compared to the first best allocation, i.e., $\lambda_{\mathrm{H}}^{*}>\lambda_{\mathrm{H}}^{\circ}$ where

$$
\lambda_{\mathrm{H}}^{*} \equiv \frac{m^{*}+n_{\mathrm{H}}^{*}}{2 m^{*}+n_{\mathrm{H}}^{*}+n_{\mathrm{F}}^{*}} \quad \text { and } \quad \lambda_{\mathrm{H}}^{\circ} \equiv \frac{m^{\circ}+n_{\mathrm{H}}^{\circ}}{2 m^{\circ}+n_{\mathrm{H}}^{\circ}+n_{\mathrm{F}}^{\circ}}
$$

Consider first the case of Ottaviano and Thisse (2004) where there exists only singleplant firms $(m=0)$. Then, $\lambda_{\mathrm{H}}^{*}>\lambda_{\mathrm{H}}^{\circ}$ is simply equivalent to $n_{\mathrm{H}}^{*}>n_{\mathrm{H}}^{\circ}$, which always holds (this can be readily verified using the expression of $n_{\mathrm{H}}^{\circ}$ given in Appendix B). Therefore, excess agglomeration takes place in single-plant configurations, for instance, when costs of second plants are large or transport costs are small.

In the presence of multi-plant firms, under-agglomeration may occur in the sense that too few plants are located in the larger country. Consider the simple case where $A_{\mathrm{H}}>B_{\mathrm{H}}$ and where $\xi f$ exceeds only slightly $B_{\mathrm{H}}$. We then get $n_{\mathrm{H}}^{*}=n_{\mathrm{F}}^{*}=n_{\mathrm{F}}^{\circ}=0<n_{\mathrm{H}}^{\circ}$, which implies that $\lambda_{\mathrm{H}}^{*}=1 / 2$ and that $\lambda_{\mathrm{H}}^{\circ}=\left(m^{\circ}+n_{\mathrm{H}}^{\circ}\right) /\left(2 m^{\circ}+n_{\mathrm{H}}^{\circ}\right)>1 / 2$. Therefore, in equilibrium the larger country hosts fewer plants than in the first-best so that under-

\footnotetext{
${ }^{8}$ Yet, distributional issues are still likely to be very important from the individual countries' points of view.
} 
agglomeration occurs.

\section{INSERT FIGURE 7}

As shown by Figure 7, when $\xi f$ increases the economy goes through two distinct phases. First, there is over-investment in multi-plant firms when fixed costs are low whereas trade costs are sufficiently high; and then there is under-investment as fixed costs increase. From a spatial perspective, this leads to a first configuration in which there is insufficient spatial polarization, whereas there is too much polarization in the other configuration. Let us summarize our findings as follows.

Proposition 2 When firms are constrained to run a single plant only, the larger country always hosts too many plants compared to the first-best. In the presence of multi-plant firms, the larger country hosts too many plants compared with the first-best when fixed costs are sufficiently low, whereas it hosts too few plants when fixed costs are sufficiently large.

Note, finally, that a reverse HME arises when fixed costs are sufficiently low. In that case, country $H$ 's share of plants actually falls below its expenditure share $\theta$, which is depicted by the dashed line in Figure 7. As fixed costs increase, the HME then progressively kicks-in for the equilibrium distribution and the first-best.

\section{Inelastic capital supply and crowding out}

Until now, we have assumed that additional capital can be raised perfectly elastically at a constant unit cost $r_{\mathrm{i}}=1$ on the world market so that the masses of firms and varieties are fixed. Although analytically convenient, this assumption neglects the fact that entry plays an important role in the markets with differentiated products, and that the price of capital is endogenous and, therefore, may differ across countries and influence the spatial and organizational allocation of firms. 
In this section, we analyze the implications of a less than perfectly elastic supply of capital which imply variable masses of firms and varieties. To keep things simple, we assume that the economy includes only a single industry, the one considered in this model. Capital is inelastic supplied and equal to the sum $K$ of individuals' endowments (Ottaviano and Thisse, 2004). The capital market clears when

$$
n_{\mathrm{H}}+n_{\mathrm{F}}+m(1+\xi)=K / f
$$

Plugging (18) into expression (3), we readily get

$$
N=K / f-\xi m
$$

Since $N$ is the mass of available varieties, expression (19) concisely highlights the presence of a crowding out effect: the mass of varieties decreases with the mass of multinationals, since they require more capital but do not add more product variety. When there are only multinationals, the global economy hosts $N=K /(f(1+\xi))$ firms, whereas it hosts $N=K / f$ firms when there are only exporters. In this respect, our model differs from standard NEG models, in which the mass of firms is usually fixed (e.g., Krugman, 1991; Ottaviano et al., 2002).

Let $r_{\mathrm{H}}, r_{\mathrm{F}}$ and $r_{\mathrm{m}}$ denote the (endogenously determined) rental rates of capital for single-plant firms in countries $H$ and $F$, and for multi-plant firms, respectively. Perfect capital mobility and free entry of firms in the differentiated industry imply that the return to capital absorbs all operating profits in equilibrium. Hence, the rental rate of capital is given by

$$
r_{\mathrm{H}}\left(n_{\mathrm{H}}, n_{\mathrm{F}}, m\right)=\frac{b+c N}{f}^{\mathbf{f}} \theta\left(p_{\mathrm{HH}}^{*}\right)^{2}+(1-\theta)\left(p_{\mathrm{HF}}^{*}-\tau\right)^{2^{\not \alpha}}
$$

in country $H$, with a symmetric expression holding for country $F$. The rental rate for a multi-plant firm is simply equal to

$$
r_{\mathrm{m}}\left(n_{\mathrm{H}}, n_{\mathrm{F}}, m\right)=\frac{b+c N}{(1+\xi) f} \stackrel{f}{f}\left(p_{\mathrm{H} H}^{*}\right)^{2}+(1-\theta)\left(p_{\mathrm{F} \mathrm{F}}^{*}\right)^{2^{\mathfrak{\alpha}}} .
$$


Under a global and perfectly integrated capital market, each individual allocates her capital to the project with the highest rate of return. Focusing on interior solutions only, where both countries host some firms, there is a unique equilibrium rental rate $r^{*}=\max \left\{r_{\mathrm{H}}, r_{\mathrm{F}}, r_{\mathrm{m}}\right\}$.

The spatial and organizational allocation of capital equalizes the rental rates capital can fetch in the two countries. It is readily verified that

$$
\begin{aligned}
& r_{\mathrm{H}}^{*}-r_{\mathrm{F}}^{*}=\frac{\tau(b+c N)}{f}{ }^{\mathrm{h}^{3}} p_{\mathrm{H} \mathrm{H}}^{*}-\frac{\tau^{\prime}}{4}-(1-\theta)^{3} p_{\mathrm{FF}}^{*}-\frac{\tau}{4}^{\prime} \mathrm{i}, \\
& r_{\mathrm{H}}^{*}-r_{\mathrm{m}}^{*}=\frac{(b+c N)}{f} \frac{\xi}{1+\xi} \stackrel{f}{\theta}\left(p_{\mathrm{HH}}^{*}\right)^{2} \\
& +(1-\theta) p_{\mathrm{FF}}^{*}-\frac{\tau}{2} \frac{1+\xi^{\mathfrak{l}_{2}}}{\xi}-(1-\theta) \frac{\tau^{2}}{4} \frac{1+\xi}{\xi^{2}},
\end{aligned}
$$

a symmetric expression holding for $r_{\mathrm{F}}^{*}-r_{\mathrm{m}}^{*}$. Figure 8 depicts the loci where the previous two conditions hold with equality in $\left(p_{\mathrm{HH}}^{*}, p_{\mathrm{FF}}^{*}\right)$-space.

\section{INSERT FIGURE 8}

The qualitative analysis is similar to the one developed in the previous sections, albeit more complex. Since $\theta \geq 1 / 2$, single-plant firms locate in country $H$, whenever they exist, so that only the following four equilibria may arise: (i) Pure multi-plant when $r_{\mathrm{m}}^{*}>r_{\mathrm{H}}^{*}$ and $r_{\mathrm{m}}^{*}>r_{\mathrm{F}}^{*}$, which corresponds to the area $m$ in Figure 8; (ii) pure single-plant in $H$ when $r_{\mathrm{H}}^{*}>r_{\mathrm{m}}^{*}$ and $r_{\mathrm{H}}^{*}>r_{\mathrm{F}}^{*}$, which corresponds to the area $H$ in Figure 7; (iii) mixedplant with single-plant agglomeration when $r_{\mathrm{H}}^{*}=r_{\mathrm{m}}^{*}$ and $r_{\mathrm{H}}^{*}>r_{\mathrm{F}}^{*}$, which correspond to the border between areas $m$ and $H$ in Figure 8; and (iv) mixed-plant with partial singleplant agglomeration when $r_{\mathrm{H}}^{*}=r_{\mathrm{F}}^{*}=r_{\mathrm{m}}^{*}$, corresponding to the point $S$ at the border of the areas $m, H$ and $F$ in Figure 7 .

Concerning the first-best, the government's objective is still given by expression (15), adding simply the new constraint (19). Hence, we may solve this problem in the same way as before. 
The general analysis with a variable mass of firms is unfortunately quite cumbersome. Yet, numerical simulations reveal the following. First, the comparative static results are similar to the ones derived before. Larger demand ( $a$ or $L$ ), higher trade costs $\tau$ and lower costs for a second plant $\xi$ all favor the emergence of multi-plant firms in equilibrium. Second, our main results, namely the existence of over-investment and under-agglomeration, continue to hold in this setting. To see this, assume that $\alpha=1, \beta=1, \gamma=0.8, L=10$, $K=10, \theta=0.5, \xi=0.55, \tau=0.07$ and $f=1$. Because countries are of equal size, $n_{\mathrm{H}}^{*}=n_{\mathrm{F}}^{*}$ will hold at any equilibrium. It is readily verified that this set of parameter values yields a pure multi-plant equilibrium: $n_{\mathrm{H}}^{*}=n_{\mathrm{F}}^{*}=0$ and $m^{*}=6.452$. The rental rate of capital is $r_{\mathrm{m}}^{*}=0.04172$, which is higher than the returns to a (hypothetical) single-plant firm in either country.

Turing to the first-best allocation it is given by a mix of single- and multi-plant firms: $n_{\mathrm{H}}^{\circ}=n_{\mathrm{F}}^{\circ}=1.454$ and $m^{\circ}=4.575$.

Several remarks are in order. First, the market outcome clearly yields over-investment, since the welfare maximizing planner would reduce the mass of multinationals and run a bunch of single-plant firms in each country. By doing so, the mass of available varieties increases from $N^{*}=6.452$ to $N^{\circ}=7.484$, thereby raising consumer surplus via the variety effect.

Since we assumed that $\theta=1 / 2$, the previous example does not reveal the case of under-agglomeration. Assume now that the new set of parameter values is as follows: $\alpha=1, \beta=1, \gamma=0.77, L=10, K=10, \theta=0.51, \xi=0.25, \tau=0.065$ and $f=1$. It is readily verified that there is again a pure multi-plant equilibrium: $n_{\mathrm{H}}^{*}=n_{\mathrm{F}}^{*}=0$ and $m^{*}=8$. The first-best allocation is again given by a mix of single- and multi-plant firms: $n_{\mathrm{H}}^{\circ}=0.115, n_{\mathrm{F}}^{\circ}=0.094$ and $m^{\circ}=7.832$. Using expression (17), we have $\lambda^{*}=0.5$ whereas $\lambda^{\circ}>0.5$, which reveals the presence of under-agglomeration in equilibrium. 


\section{Conclusion}

We have developed a fully solvable model of horizontal FDI in which firms endogenously choose both their location and their production structure. Our findings confirm those of the existing literature, namely that firms will operate multiple production plants when fixed costs are sufficiently low and/or when transport costs are high. Yet, we have also shown that price competition matters in shaping firms' decisions. Indeed, when more firms 'go multinational', price competition erodes the ability of exporting firms to profitably penetrate the foreign markets, thereby enticing them to become themselves multinational. As shown by the welfare analysis, this may then lead to situations in which too many multinationals operate in the global economy, thereby leading to an excessive waste of resources. This finding is opposed to those derived in the CES model, in which there is always a suboptimally low mass of multi-plant firms in equilibrium due to the absence of pro-competitive effects (Toulemonde, 2004).

We have also shown that the occurrence of excess-agglomeration strongly depends on whether multi-plant operation is allowed in the economy or not. Indeed, when all firms are single-plant, there will be excessive agglomeration in equilibrium, whereas the reverse may be true in the presence of multinationals. This suggests that the general perception that modern economies are over-agglomerated may require some drastic qualifications, given that multi-plant operation is the rule and not the exception in the real world.

\section{References}

[1] Baldwin, R.E., R. Forslid, Ph. Martin, G.I.P. Ottaviano and F. Robert-Nicoud (2003) Economic Geography and Public Policy. Princeton: Princeton Univ. Press.

[2] Barba Navaretti, G.B. and A.J. Venables (2004) Multinational firms in the world economy. Princeton, NJ: Princeton Univ. Press. 
[3] Brainard, S.L. (1997) An empirical assessment of the proximity-concentration tradeoff between multinational sales and trade, American Economic Review 87, 520-544.

[4] Davis, D. and D. Weinstein (2003) Market access, economic geography and comparative advantage: an empirical test, Journal of International Economics 59, 1-23.

[5] Dunning, J.H. (1993) Multinational Enterprises and the Global Economy. London: Addison Wesley Publishers.

[6] Ekholm, K. and R. Forslid (2001) Trade location with horizontal and vertical multiregion firms, Scandinavian Journal of Economics 103, 101-118.

[7] Fujita, M. and J.-F. Thisse (2005) Globalization and the evolution of the supply chain: who gains and who loses? Forthcoming in International Economic Review.

[8] Haaland, J.I. and I. Wooton (2000) Multinational firms: Easy come, easy go? NHH Discussion Paper 19/2000.

[9] Haskel, J. and H. Wolf (2001) The law of one price - A case study, Scandinavian Journal of Economics 103, 545-558.

[10] Haufler, A. and I. Wooton (1999) Country size and tax competition for foreign direct investment, Journal of Public Economics 71, 121-139.

[11] Head, K. and T. Mayer (2000) Non-Europe. The magnitude and causes of market fragmentation in the EU, Weltwirtschaftliches Archiv 136, 284-314.

[12] Head, K., T. Mayer and J. Ries (2002) On the pervasiveness of home market effects, Economica 69, 371-390.

[13] Head, K., and J. Ries (2003) Increasing returns vs national product differentiation as an explanation for the pattern of US-Canada trade, American Economic Review $91,858-876$. 
[14] Helpman, E. and P.R. Krugman (1985) Market Structure and Foreign Trade. Cambridge, MA: MIT Press.

[15] Krugman, P.R. (1980) Scale economies, product differentiation and the pattern of trade, American Economic Review 70, 950-959.

[16] Krugman, P.R. (1981) Intraindustry specialization and the gains from trade, Journal of Political Economy 89, 959-974.

[17] Markusen, J.R. and A.J. Venables (1998) Multinational firms and the new trade theory, Journal of International Economics 46, 183-203.

[18] Markusen, J.R. and A.J. Venables (1999) Foreign direct investment as a catalyst for industrial development, European Economic Review 43, 335-356.

[19] Markusen, J.R. and A.J. Venables (2000) The theory of endowment, intra-industry and multi-national trade, Journal of International Economics 52, 209-234.

[20] OECD (2004) Recent trends in foreign direct investment in OECD countries. OECD, Directorate for Financial and Enterprise Affairs.

[21] Ottaviano, G.I.P., T. Tabuchi and J.-F. Thisse (2002) Agglomeration and trade revisited, International Economic Review 43, 409-436.

[22] Ottaviano, G.I.P., and J.-F. Thisse (2002) Integration, agglomeration and the political economics of factor mobility, Journal of Public Economics 83, 429-456.

[23] Ottaviano, G.I.P. and J.-F. Thisse (2004) Agglomeration and economic geography. In: Henderson, J.V. and J.-F. Thisse (eds.). Handbook of Regional and Urban Economics, Volume IV (Amsterdam, North-Holland), pp. 2563-2608.

[24] Raybaudi-Massilia, M. (2000) Economic geography and multinational entreprise, Review of International Economics 8, 1-19. 
[25] Toulemonde, E. (2004) Multinationals: too many or too few? Université de Lausanne, mimeographed.

\section{Appendix A: Spatial equilibrium}

In this appendix, we derive the spatial equilibrium as a function of $\xi f$. First we consider the case with small size asymmetries $\theta \leq \bar{\theta}$. Given the thresholds $A_{\mathrm{H}}<A_{\mathrm{F}}<A_{0}$, we get the following proposition:

Proposition 3 (equilibrium with small size asymmetry) Assume that size asymmetries are sufficiently small, i.e., $\theta<\bar{\theta}$. Then,

(1a) if $\xi f<A_{\mathrm{H}}<A_{\mathrm{F}}$, there is a pure multi-plant equilibrium such that $n_{\mathrm{H}}=n_{\mathrm{F}}=0$ and $m=N$;

(1b) if $A_{\mathrm{H}}<\xi f<A_{\mathrm{F}}<A_{0}$, there is a mixed equilibrium $n_{\mathrm{H}}=\bar{n}_{\mathrm{H}}$ and $m=N-\bar{n}_{\mathrm{H}}$;

(1c) if $A_{\mathrm{H}}<A_{\mathrm{F}}<\xi f<A_{0}$, there is an interior equilibrium $n_{\mathrm{H}}=\bar{n}_{\mathrm{H}}, n_{\mathrm{F}}=\bar{n}_{\mathrm{F}}$ and $m=N-\bar{n}_{\mathrm{H}}-\bar{n}_{\mathrm{F}} ;$

(1d) if $A_{\mathrm{H}}<A_{\mathrm{F}}<A_{0}<\xi f$, there is a pure single-plant equilibrium $n_{\mathrm{H}}=n_{\mathrm{H}}^{*}, n_{\mathrm{F}}=n_{\mathrm{F}}^{*}$ and $m=0$.

Proof. The following cases need to be distinguished:

(i) Assume that $\xi f<A_{\mathrm{H}}$. This leads to a pure multi-plant equilibrium $m=N, n_{\mathrm{H}}=0$ and $n_{\mathrm{F}}=0$, because $\bar{n}_{\mathrm{H}}<0$ and $\bar{n}_{\mathrm{F}}<0$. Conditions (12) and (13) then show that $\Pi^{\mathrm{m}}>\Pi_{\mathrm{H}}^{\mathrm{s}}$ and $\Pi^{\mathrm{m}}>\Pi_{\mathrm{F}}^{\mathrm{s}}$ for all values of $n_{\mathrm{H}}$ and $n_{\mathrm{F}}$, hence also for $n_{\mathrm{H}}=n_{\mathrm{F}}=0$ and $m=N$. 
(ii) Assume that $A_{\mathrm{H}}<\xi f<A_{\mathrm{F}}$, so that $\bar{n}_{\mathrm{F}}<0<\bar{n}_{\mathrm{H}}$. Clearly, $n_{\mathrm{F}}=0$ must hold in all cases. If $n_{\mathrm{H}}<\bar{n}_{\mathrm{H}}$, then $n_{\mathrm{H}}=N$ and $m=0$. This is only feasible when $N<\bar{n}_{\mathrm{H}}$, which will be the case when

$$
N<\frac{4 a-(2 b+c N) \tau}{2 c \tau} \frac{2 \theta-1}{1-\theta} \quad \Longleftrightarrow \quad \bar{\theta}<\theta
$$

which is false. The case $n_{\mathrm{H}}>\bar{n}_{\mathrm{H}}$ cannot arise, since in that case $n_{\mathrm{H}}=0$, which is impossible since $\bar{n}_{\mathrm{H}}>0$. We finally have the case $n_{\mathrm{H}}=\bar{n}_{\mathrm{H}}, n_{\mathrm{F}}=0$ and $m=N-\bar{n}_{\mathrm{H}}$, which is possible if and only if $\bar{n}_{\mathrm{H}} \leq N$. This holds provided that

$$
N \geq \frac{4 a-(2 b+c N) \tau}{2 c \tau} \frac{2 \theta-1}{1-\theta} \quad \Longleftrightarrow \quad \theta \leq \bar{\theta}
$$

which holds by assumption in this case.

(iii) Assume that $A_{\mathrm{F}}<\xi f<A_{0}$, so that $0<\bar{n}_{\mathrm{F}}<\bar{n}_{\mathrm{H}}$. Note that the cases $n_{\mathrm{H}} \geq \bar{n}_{\mathrm{H}}$ and $n_{\mathrm{F}}>\bar{n}_{\mathrm{F}}$ (resp. $n_{\mathrm{H}}>\bar{n}_{\mathrm{H}}$ and $n_{\mathrm{F}} \geq \bar{n}_{\mathrm{F}}$ ) are impossible, since they would imply that $n_{\mathrm{F}}=0$ (resp. $\left.n_{\mathrm{H}}=0\right)$. Analogously, the two cases $n_{\mathrm{H}}<\bar{n}_{\mathrm{H}}$ and $n_{\mathrm{F}} \geq \bar{n}_{\mathrm{F}}$ (resp. $n_{\mathrm{H}} \geq \bar{n}_{\mathrm{H}}$ and $\left.n_{\mathrm{F}}<\bar{n}_{\mathrm{F}}\right)$ can be ruled out for similar reasons, since they imply that $n_{\mathrm{F}}=0$ (resp. $\left.n_{\mathrm{H}}=0\right)$.

Assume next that $n_{\mathrm{F}}<\bar{n}_{\mathrm{F}}$ and $n_{\mathrm{H}}<\bar{n}_{\mathrm{H}}$. When this is true, $\Pi^{\mathrm{m}}<\Pi_{\mathrm{H}}^{\mathrm{S}}$ and $\Pi^{\mathrm{m}}<\Pi_{\mathrm{F}}^{\mathrm{S}}$ so that $m=0$. When $\Pi_{\mathrm{H}}^{\mathrm{s}}=\Pi_{\mathrm{F}}^{\mathrm{s}}$, we get an interior solution provided that $\xi f>A_{0}$, which does not hold in this case by assumption. Thus, the only remaining possibility is a corner solution with $n_{\mathrm{H}}=N$, which is feasible when $\bar{n}_{\mathrm{H}}>N$, i.e., when condition (22) holds. Similarly, when $n_{\mathrm{F}} \leq \bar{n}_{\mathrm{F}}$ and $n_{\mathrm{H}}>\bar{n}_{\mathrm{H}}$, we have $n_{\mathrm{F}}=N$. It is readily verified that $\bar{n}_{\mathrm{F}}>N$ must then hold, which requires that

$$
\xi f>\frac{(b+c N)(2 a-b \tau)}{2(2 b+c N)} L \tau \theta>A_{0}
$$

which does not hold in this case. Finally, assume that $n_{\mathrm{H}}=\bar{n}_{\mathrm{H}}$ and $n_{\mathrm{F}}=\bar{n}_{\mathrm{F}}$, with $m=N-\bar{n}_{\mathrm{H}}-\bar{n}_{\mathrm{F}}$. This is feasible if and only if $m \geq 0$, which requires that $\xi f<A_{0}$ and, therefore, holds. 
(iv) Assume, finally, that $A_{0}<\xi f$, so that $\bar{n}_{\mathrm{F}}<\bar{n}_{\mathrm{H}}<0$. In this case, we have a pure single-plant equilibrium $\left(n_{\mathrm{H}}^{*}, n_{\mathrm{F}}^{*}\right)$ as derived in Section 3. This will be an interior equilibrium if and only if $n_{\mathrm{H}}^{*}<N$ and it will be a corner equilibrium $n_{\mathrm{H}}^{*}=N$ and $n_{\mathrm{F}}^{*}=0$ otherwise. For this to be feasible, we have to compare $n_{\mathrm{H}}^{*}$ with $\bar{n}_{\mathrm{H}}$ (resp. $n_{\mathrm{F}}^{*}$ with $\bar{n}_{\mathrm{F}}$ ). One can readily verify that

$$
n_{\mathrm{H}}^{*}<\bar{n}_{\mathrm{H}} \quad \Longleftrightarrow \quad \xi f>A_{0} \equiv \frac{(2 a-\tau b)(b+c N)}{2 b+c N} \tau L \theta(1-\theta),
$$

and that $n_{\mathrm{F}}^{*}<\bar{n}_{\mathrm{F}}$ holds under the same condition. When (24) is satisfied, no firm in any country has an incentive to build a second plant, so that a pure single-plant equilibrium $\left(n_{\mathrm{H}}^{*}, n_{\mathrm{F}}^{*}\right)$ can be sustained.

Consider next the case with large size asymmetries $\theta>\bar{\theta}$. Given the thresholds $A_{\mathrm{H}}<A_{0}<A_{\mathrm{F}}$, we have the following proposition:

Proposition 4 (equilibrium with large size asymmetry) Assume that size asymmetries are sufficiently large, i.e., $\theta>\bar{\theta}$. Then,

(2a) if $\xi f<A_{\mathrm{H}}<A_{\mathrm{F}}$, there is a pure multi-plant equilibrium such that $n_{\mathrm{H}}=n_{\mathrm{F}}=0$ and $m=N$;

(2b) if $A_{\mathrm{H}}<\xi f$, there is a pure single-plant equilibrium with full agglomeration $n_{\mathrm{H}}=N$, $n_{\mathrm{F}}=0$ and $m=0$.

Proof. The following cases need to be distinguished:

(i) If $\xi f<A_{\mathrm{H}}$ we have a pure multi-plant equilibrium for the same reason as in (A.1.) above.

(ii) If $A_{\mathrm{H}}<\xi f<A_{\mathrm{F}}$, we know that $\bar{n}_{\mathrm{F}}<0<\bar{n}_{\mathrm{H}}$. Using the same argument as in (A.1.) above, we then get $n_{\mathrm{H}}=N$ and $m=n_{\mathrm{F}}=0$. This is because $N<\bar{n}_{\mathrm{H}}$, which must be true since (22) holds in this case.

(iii) Finally, when $A_{\mathrm{F}}<\xi f$, we have a pure single-plant equilibrium $\left(n_{\mathrm{H}}^{*}, n_{\mathrm{F}}^{*}\right)$ as in (A.1.) above. Since $\theta>\bar{\theta}$, it is then readily verified that $n_{\mathrm{H}}^{*}=N$ and $n_{\mathrm{F}}^{*}=0$. 


\section{Appendix B: Optimum}

In this appendix, we derive the different configurations for the first best. The planner's problem is given by:

$$
\begin{aligned}
\max _{\mathrm{n}_{\mathrm{H}}, \mathrm{n}_{\mathrm{F}}, \mathrm{m}} W \equiv & L\left[\theta S_{\mathrm{H}}+(1-\theta) S_{\mathrm{F}}\right]-f\left(n_{\mathrm{H}}+n_{\mathrm{F}}\right)-m(1+\xi) f . \\
\text { s.t. } & n_{\mathrm{H}}+n_{\mathrm{F}}+m=N \\
& n_{\mathrm{H}} \geq 0, n_{\mathrm{F}} \geq 0, m \geq 0
\end{aligned}
$$

where $S_{\mathrm{H}}$ is given by (16). Concerning the global ranking of all four thresholds, we need to distinguish the following two cases: (i) $\theta \leq \theta^{\circ}$; and (ii) $\theta>\theta^{\circ}$. One can check that in case (i) the global ranking is as follows: $B_{\mathrm{H}}<B_{\mathrm{F}}<B_{0}<B_{1}$; whereas in case (ii) the global ranking satisfies $B_{\mathrm{H}}<B_{1}<B_{0}<B_{\mathrm{F}}$.

Proposition 5 (optimum outcome) Suppose that the size asymmetries are sufficiently small, i.e., $\theta<\theta^{\circ}$. Then we have

(3a) if $\xi f \leq B_{\mathrm{H}}, n_{\mathrm{H}}^{\circ}=n_{\mathrm{F}}^{\circ}=0$ and $m^{\circ}=N$;

(3b) if $B_{\mathrm{H}}<\xi f \leq B_{\mathrm{F}}, n_{\mathrm{H}}^{\circ}>0, n_{\mathrm{F}}^{\circ}=0$ and $m^{\circ}>0$;

(3c) if $B_{\mathrm{F}}<\xi f \leq B_{0}, n_{\mathrm{H}}^{\circ}>0, n_{\mathrm{F}}^{\circ}>0$ and $m^{\circ}>0$;

(3d) if $\xi f>B_{0}, n_{\mathrm{H}}^{\circ}>0, n_{\mathrm{F}}^{\circ}>0$ and $m^{\circ}=0$.

Suppose that the size asymmetries are sufficiently large, i.e., $\theta>\theta^{\circ}$. Then we have

(4a) if $\xi f \leq B_{\mathrm{H}}, n_{\mathrm{H}}^{\circ}=n_{\mathrm{F}}^{\circ}=0$ and $m^{\circ}=N$;

(4b) if $B_{\mathrm{H}}<\xi f \leq B_{1}, n_{\mathrm{H}}^{\circ}>0, n_{\mathrm{F}}^{\circ}=0$ and $m^{\circ}>0$;

(4c) if $\xi f>B_{1}, n_{\mathrm{H}}^{\circ}=N, n_{\mathrm{F}}^{\circ}=0$ and $m^{\circ}=0$ : 
Proof. The following cases may arise:

(i) Corner solution $n_{\mathrm{H}}^{\circ}=0, n_{\mathrm{F}}^{\circ}=0$ and $m^{\circ}=N$ with only multi-plant firms. It is readily verified that this is feasible if and only if $\xi f<B_{\mathrm{H}}$.

(ii) Corner solution $n_{\mathrm{H}}^{\circ}>0, n_{\mathrm{F}}^{\circ}=0$, and $m^{\circ}>0$ with single-plant firms in $H$ and multi-plant firms. In that case,

$$
n_{\mathrm{H}}^{\circ}=\frac{\xi f}{L c \tau^{2}(1-\theta)}-\frac{2 a-(b+c N) \tau}{2 c \tau}, \quad n_{\mathrm{F}}^{\circ}=0, \quad m^{\circ}=N-n_{\mathrm{H}}^{\circ}
$$

which is feasible if and only if $B_{\mathrm{H}} \leq \xi f \leq \max \left\{B_{\mathrm{F}}, B_{1}\right\}$. Note that this is always a non-empty interval when $\theta>1 / 2$.

(iii) Interior mixed solution $n_{\mathrm{H}}^{\circ}>0, n_{\mathrm{F}}^{\circ}>0$ and $m^{\circ}>0$. It is readily verified that this solution is given by

$$
\begin{array}{r}
n_{\mathrm{H}}^{\circ}=\frac{\xi f}{L c \tau^{2}(1-\theta)}-\frac{2 a-(b+c N) \tau}{2 c \tau} \\
n_{\mathrm{F}}^{\circ}=\frac{\xi f}{L c \tau^{2} \theta}-\frac{2 a-(b+c N) \tau}{2 c \tau}
\end{array}
$$

and $m^{\circ}=N-n_{\mathrm{H}}^{\circ}-n_{\mathrm{F}}^{\circ}$, which is feasible if and only if $B_{\mathrm{F}} \leq \xi f \leq B_{0}$. This case may arise only when $\theta<\theta^{\circ}$, in which case the above interval is non-empty. Hence, an interior equilibrium is a first best outcome if and only if size asymmetries are not too large.

(iv) Corner solution $n_{\mathrm{H}}^{\circ}=N, n_{\mathrm{F}}^{\circ}=0$ and $m^{\circ}=0$, which is feasible if and only if $B_{1} \leq \xi f \leq B_{\mathrm{F}}$. This case may therefore only arise when $\theta>\theta^{\circ}$, in which case the above interval is non-empty. Therefore, full agglomeration of only single-plant firms in the larger market is a first best outcome if and only if size asymmetries are sufficiently large.

(v) Pure single-plant solution $n_{\mathrm{H}}^{\circ}>0, n_{\mathrm{F}}^{\circ}>0$, and $m^{\circ}=0$. In that case,

$$
n_{\mathrm{H}}^{\circ}=\frac{N}{2}+\frac{(2 a-b \tau)}{2 c \tau}(2 \theta-1), \quad n_{\mathrm{F}}^{\circ}=\frac{N}{2}-\frac{(2 a-b \tau)}{2 c \tau}(2 \theta-1)
$$

and $m^{\circ}=0$, which is feasible if and only if $\max \left\{B_{0}, B_{\mathrm{F}}\right\} \leq \xi f$. It is readily verified that

$$
\frac{n_{\mathrm{H}}^{\circ}-n_{\mathrm{F}}^{\circ}}{N}=(2 \theta-1) \frac{2 a-b \tau}{c \tau N}
$$


which, when compared with (14) shows that the planner will choose less agglomeration than the market outcome. Hence, the market outcome in the pure single-plant case yields too much agglomeration. 


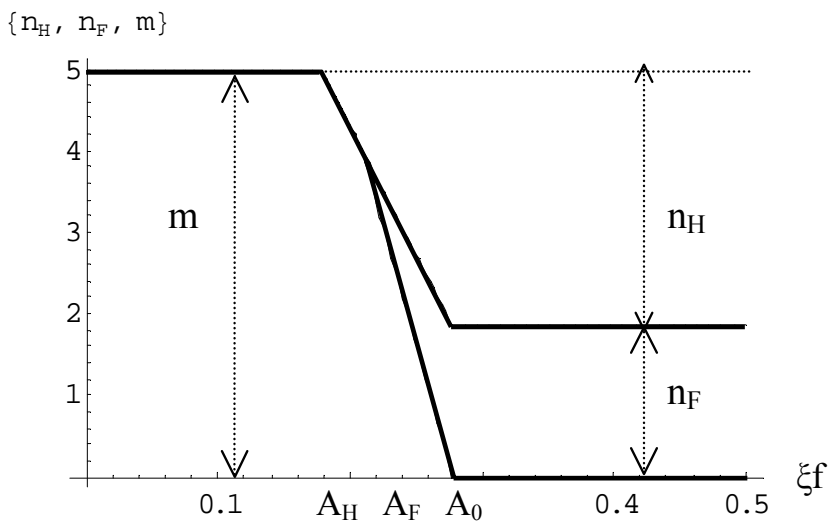

Fig. 1: Equilibrium (small $\theta$ )

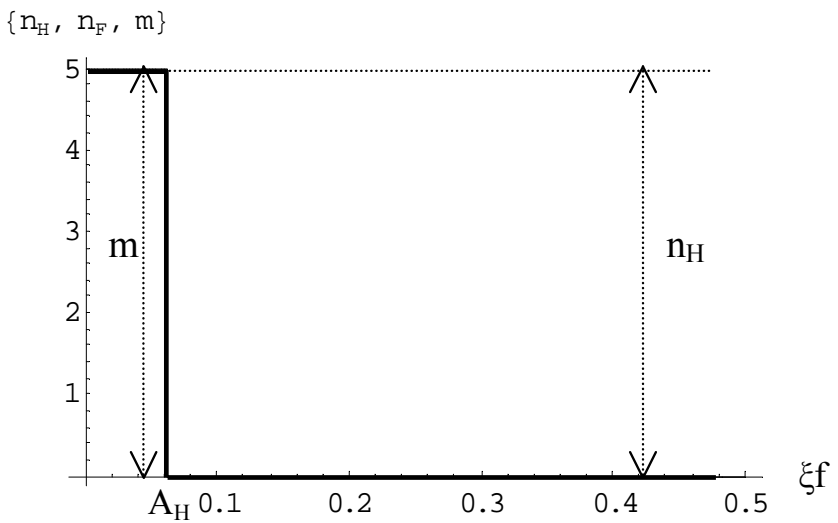

Fig. 2: Equilibrium (large $\theta$ ) 


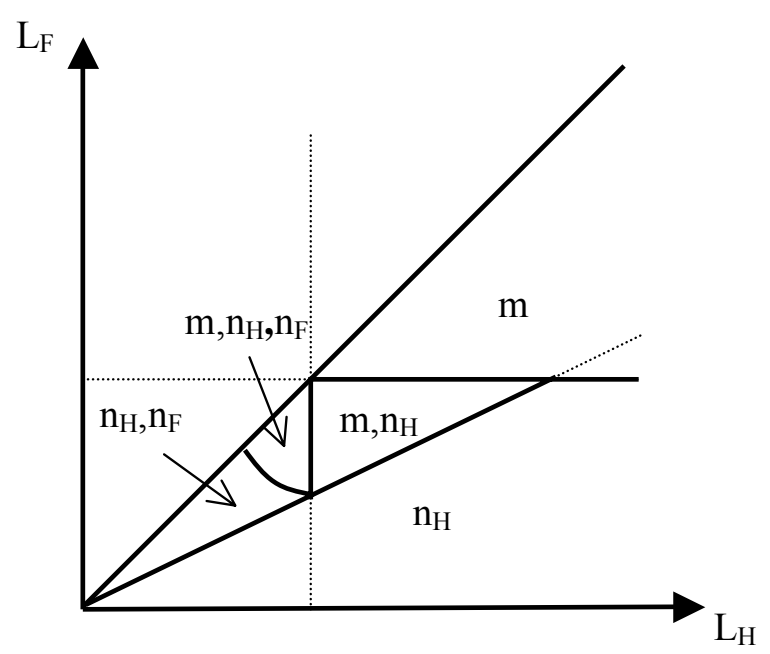

Fig. 3: Equilibrium configuration and country sizes 


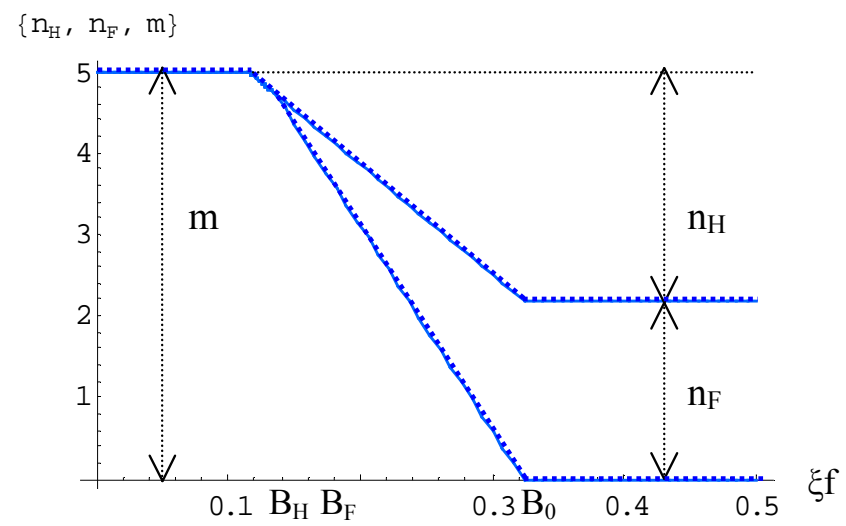

Fig. 4: First best (small $\theta$ )

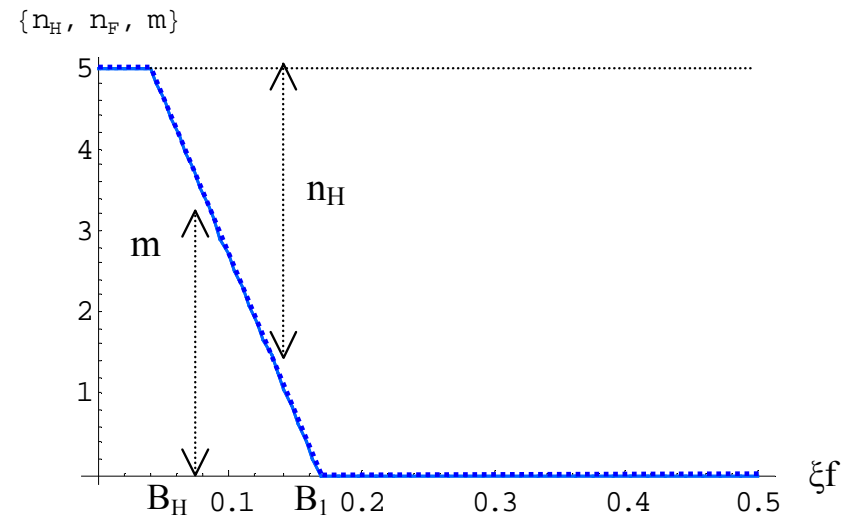

Fig. 5: First best (large $\theta$ ) 


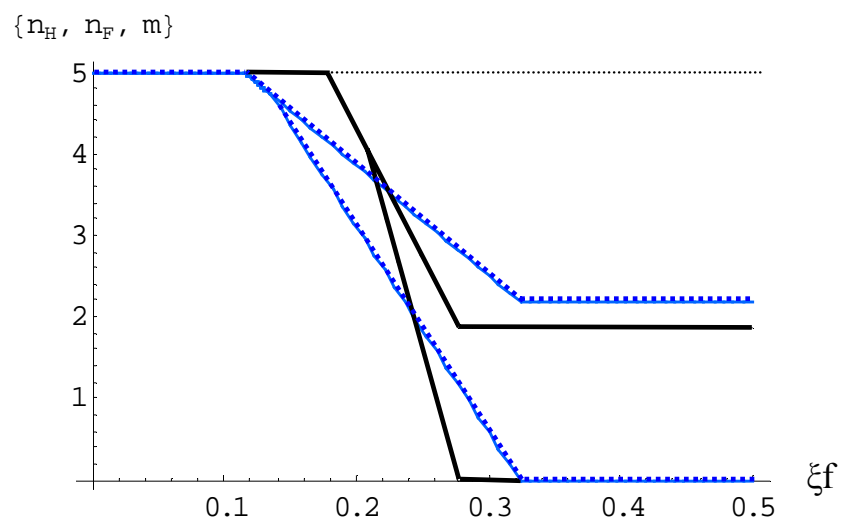

Fig. 6: Equilibrium and first best (small $\theta$ )

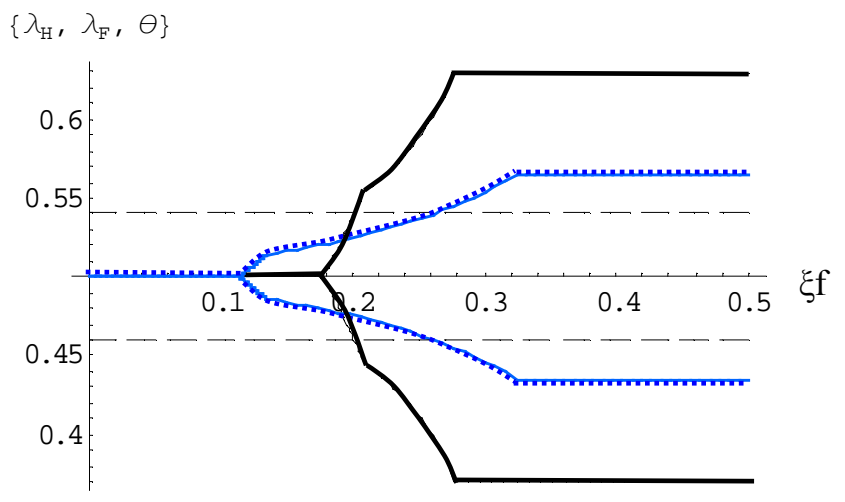

Fig. 7: Relative number of plants in each country: equilibrium and first best (small $\theta)$ 


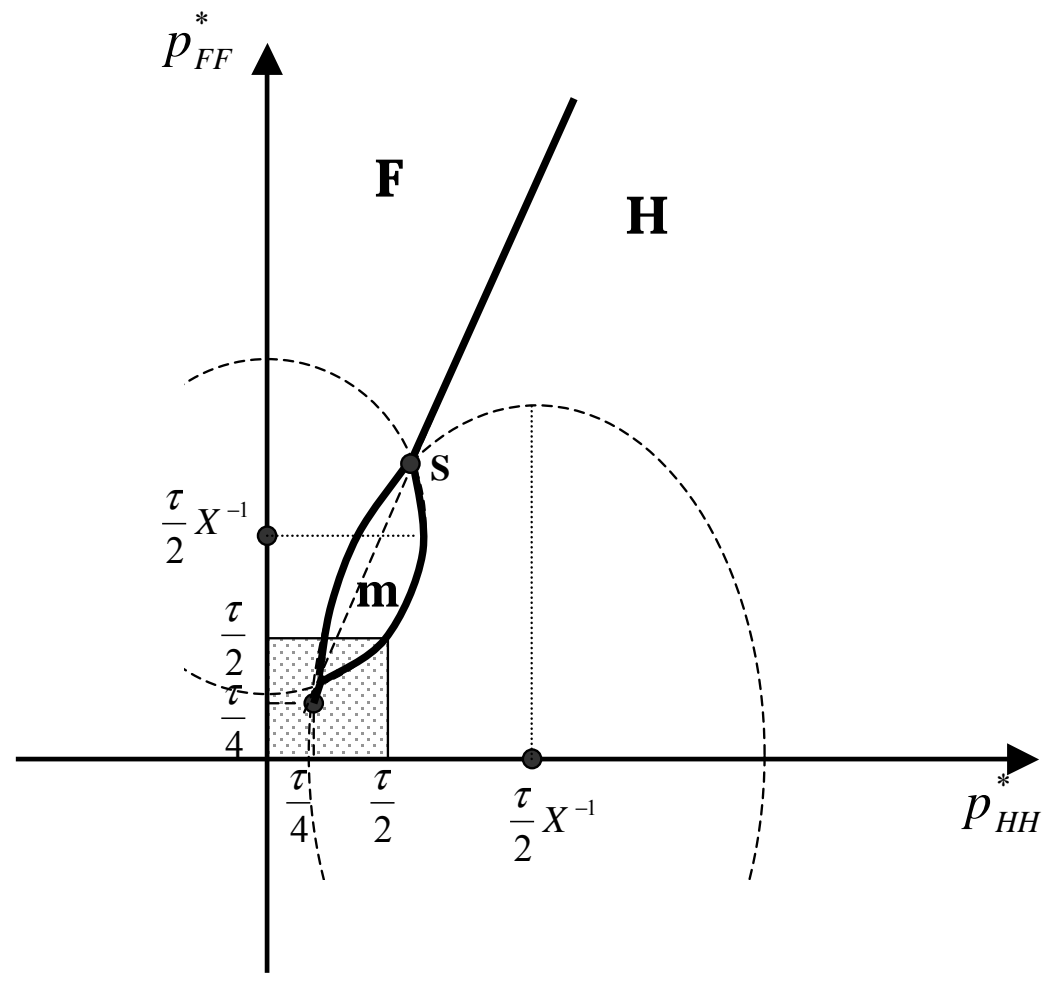

Fig. 8 : Rental rates and product prices 